\title{
The Effectiveness of Using Electronic Mind Maps to Develop Students' Knowledge of Multimedia Concepts at Al Baha University
}

\author{
Dr. Abdullah K Alodail \\ Associate Professor, College of Education, Al-Baha University \\ Alodail1@hotmail.com
}

\begin{abstract}
. the emergence of web 2.0 technologies has created new opportunities in the field of multimedia concepts. Electronic mind maps are used to present information in an interesting and fast format, save time and keep learners from becoming bored. Electronic mind maps are a valuable platform for learning multimedia concepts in class activities and as out-of-class assignments to increase learners' achievements. Therefore, this research focuses on designing electronic mind maps (using XMind) to teach multimedia concepts among undergraduate students at the College of Education at Al-Baha University. The study aimed to detect the effect of e-mind maps on increasing students' achievements. The study used a quasiexperimental approach to prepare the literature framework and a measurement tool including an achievement test. The study sample consisted of 40 learners. The researcher used a t-test to measure the differences between the experimental group, which was taught using e-mind maps (text and image), and the control group, which was taught using a traditional method. The results revealed that there was a significant difference in the level of $\alpha \leq 0.05$ in relation to the experimental group taught by e-mind maps, with an arithmetic average of 28.25 in the post achievement test .Therefore, the study recommended working with e-mind maps, which contain photos and texts when teaching instructional design at the university, and measuring its effect on acquiring some concepts of multimedia.
\end{abstract}

Key Words: Effectiveness; Computerized mental diagrams; Mixed media; Al Baha University

\section{Introduction}

The history of technology was divided into three principal periods prior to the twentieth century: teacher, chalkboard, and textbook. Instructional design plays a critical role in assisting teaching to increase students' achievements in Saudi Arabia. A primary task of an instructor is to customize instructional design plans, so that they may increase access to free and beneficial technology programs to help learners. Visualization culture, which includes texts, images, photos, and videos seems to be more efficient at improving students' progress, and thus more important than verbal information. Therefore, electronic mind maps have emerged as a new technique to simplify knowledge and data for learners in attractive visual shapes.

The emergence of web 2.0 technologies has led to new forms of communication and interaction with others, removing geographic limitations. That is to say, the Internet offers advanced ways of communicating such as chat rooms, video chat, web resources, presentations and electronic mind maps. Therefore, educational institutions have begun 
to use these techniques in education. Indeed, Web 2.0 tools can support and enhance interaction among students, and, in turn, this collaboration enables them to contribute to solving problems by discussing them as a larger group.

Many instructors in the world have recently been interested in developing Educational strategies in the universities, through the development of the students' performance in dealing with electronic mind maps in learning. Electronic mind maps can educate individuals how to discover stories in the data, and how to visually communicate and share them with the audience for effectiveness. A mind map is a multi-colored, image centered, radial graph that represents semantic or other connections between parts of learned material hierarchically. The electronic mind map is easy to learn how to create and apply, encourages creativity and self-expression, gives a brief hierarchical overview, and is simple to expand and add more content.

In his study of electronic mind maps, ( Elshahrany, 2010) demonstrated that experimental performed better control groups in achievements. The results recommended the electronic mind maps in teaching science. In addition, a study by (Elqasemia, 2010) revealed there were significant differences among students' achievement score in favor of the experimental group of students due to their use of mind maps. While (Wu et al., 2012) found the electronic mind-map approach can be considerably useful for improving learning achievements, as well as their attitudes to learning in comparison with the conventional concept map approach. Many instructors around the world have recently become interested in developing educational strategies at universities, specifically through the use of e-mind maps to develop students' performance. This is because they can be used effectively so they can be visually communicated and shared with the audience more successfully. The image or text defines the common pattern, which can appear in the data.

The researcher reviewed the literature related to the effectiveness of electronic mind maps on students' achievements with regard to the development of some multimedia concepts. It is important to implement new teaching methods in the educational environment to attract learners to delve into the world of multimedia concepts. Electronic mind maps have been show to affect students' achievement regarding the development of multimedia concepts, because visualizations are effective. The researcher sought to improve students' achievement using electronic mind maps in the classroom, since they present both images and text together in attractive colors and forms. Therefore, learners can process the visual data more successfully. Furthermore, motivation theory supports the use of electronic mind maps in educational process, because they have a positive impact on students' motivation to learn and pay attention.

The multimedia concepts unit, taught as part of the subject of education, were selected, and the specific subject of instructional design was chosen because it was deemed suitable for the use of electronic mind maps design (text and image) to measure the development of some multimedia concepts among students at the College of Education at Al-Baha University. The aim of this research is to identify the effect of electronic mind maps presented online in the development of a number of multimedia concepts on students of the College of Education at Al Baha University. Given the above, this study attempted to design some electronic mind maps (xmind) on the subject of instructional design and measure their impact on students' achievement.

\section{PROBLEMS WITH THE STUDY}

Although various studies have discussed the effectiveness of using electronic mind maps, 
few have been conducted in Saudi Arabia. Investigating the effectiveness of this approach on improving students' achievements at the College of Education at Al-Baha University could therefore fill a gap in the literature. The researcher conducted a pilot study to determine if there were any problems with the study, by administering a test to measure the students' knowledge of multimedia concepts. The results showed their teacher had provided a poor explanation of the subject matter.

As a result, it was found that students had a low of achievement (between 20-60\%) in both their coursework and exams in the subject of multimedia concepts, which prompted the researcher to use modern technology (multimedia concepts) to develop their academic achievement. Traditionally, mind maps have been made using paper and pens, however, the drawback of this approach is that the use of color, picture and, more specifically sound are limited. In recent years, computer software packages have been created to enable mind maps to be produce electronically, known as electronic mind maps (EMM), making it simpler to create, as branch can be replicated, simply removed if necessary, and transferred from one place to another. In addition, a wider range of colors and images can be applied, as well as sound. Many studies have confirmed the need for use of electronic mind maps to increase students' achievements such as those by (Hawrany,2011); (Elawfy,2011); (Abdel Khaliq,2012).

The researcher has worked at a faculty in the College of Education at Albaha University teaching males since 2013. Based on the researcher's experience, students' achievement has not yet reached its full potential, due to the inability of conventional methods to attract and maintain students' attention. The college has also failed to meet students' needs and provide practical training. Consequently, students of different levels of achievements have complained about their struggles to learn multimedia concepts, due to the difficulty they face when memorizing concepts, which has thus resulted in a low level of achievement among students. Therefore, a more modern and effective approach must be used to develop students' academic achievement in a way that is attractive and meets their needs. The researcher's solution was the frequent use of electronic mind maps, which he compared with a conventional method.

The researcher determined that the low level of achievement among students', in terms of the development of multimedia concepts in education was because of the difficulties created by teachers using a conventional teaching method. Therefore, it was decided that the use of modern technology, namely emind maps, is needed to improve learners' achievement with regard to multimedia concepts.

The researcher interviewed some colleagues in the field of education that teach instructional design to undergraduate students, as he was eager to know the impact of electronic mind maps on academic achievement.

The present study is the first study aimed at revealing the effectiveness of the enhanced emind map technique on students' achievement at the College of Education at Al-Baha University.

The literature advocates e-mind maps to various degrees of and discusses their impact on the learning environment. Therefore, faculty members should consider employing elearning techniques to improve learners' understanding of multimedia concepts.

\section{RESEARCH QUESTION}

The study aimed to examine the following research question:

1-How effective is the strategy of using electronic mind maps on students' achievement in terms of the topic of multimedia concepts at the College of Education at Al-Baha University?

THE ASSUMPTIONS OF THE STUDY 
1-There has no effect on learners' achievement of experimental group with electronic mind maps and control group with traditional method during the pre and post-tests as a result of implementing the program.

\section{STUDY OBJECTIVES}

In summary, the researcher aimed to:

1. Measure the effectiveness of the use of emind maps on students' achievement compared to a traditional teaching method used to teach the Multimedia Concepts Unit among a sample of students.

2. Test the significant differences between the two study groups based on teaching methods.

3. Design electronic-Mind Maps strategy for use when teaching the Multimedia Concepts Unit.

\section{THE IMPORTANCE OF THE STUDY}

Many educators are not aware of the fact emind maps have a number of advantages when teaching, specifically aiding in organizing the lesson and making it more attractive for individuals by allowing them to visualize the data. The importance of this study is due to the fact it can:

1. Improve achievement and integration among the male students studying Multimedia.

2. Attract the attention of administrators in educational institutes, and influence them change instructional techniques to improve knowledge and information across many other topics.

3. Contribute in workshops and provide training courses to improve educational process by modern emerging technologies that support in enhancing students' learning.

\section{LIMITATIONS}

The study was conducted on a sample of students who registered for the first semester of the 2019-2020 course titled "Instructional Design" at the College of Education at AlBaha University. The researcher selected the Multimedia Concepts in Education Unit to evaluate learners' achievements, because the unit contained lot of data in the form of text and image. The study aimed to detect the effect of e-mind maps on students' achievement.

\section{THE DEFINITION OF TERMS EFFECTIVNESS AND ADDIE}

Effectiveness is defined as the impact of the investigation as an independent element on the dependent factors, or an individual's need to obtain goals, feedback, and experience achievements (Jain \& Singh, 2017).

Operationally, in this study, effectiveness refers to the statistical effect on the dependent variable, that is to say, on students' progress learning the information featured in the unit titled Multimedia Concepts after using the independent variable (e-mind maps) as a teaching method.

According to (Reiser \& Dempsey,2007), the ADDIE model, which stands for analysis, design, development, implement, and evaluation, is a general process, and can be used to design a new model for an educational subject.

Operationally, it is an instructional design model that develops the teaching of subjects and programs in several ways based on five steps: analysis, design, development, implement, and evaluation.

\section{ELECTRONIC MIND MAPS}

There is a form of computerized mind map, which was used by the undergraduate students in the experimental group to support and assist them in the analysis and organization of the ideas, in order that they had better understand multimedia concepts using images, colors, and gradient curves. Moreover, students were able to insert images and colors to reform the main and sub ideas. These e-mind maps were designed using a special program: the Xmind, which was created by XMind Ltd. It can be downloaded from the apple store onto mobile phones, laptops or tablets. This program's effect was measured by the grade achieved by the student in the multimedia test prepared by the researcher for the purpose of this study. 
(Buzan,2005) defined electronic-mind maps as a powerful graphical technique that provides you with the keys to use your brain power by harnessing most of the skills of the mind, word, image, numbers, colors, logic, rhythm on every occasion.

In short, using e-mind maps is a way of transferring theoretical or written data into visual information, and can be used to organize lesson content to ensure that the information is attractive and learners understand it easily. E-mind maps can also be defined as a method to change complex data into information that can be understood easily and quickly by learners.

\section{MULTIMEDIA}

Multimedia is defined as an environment in which images, text, sound, animation, video, or a combination of these media, are used for students to access information. Indeed, using multimedia materials as an option with texts, images, animations and videos can make learning easier (Mayer, 2003)

Operationally, it is content that uses a combination of different content forms such as text and images.

\section{LITERATURE REVIEW}

Given our brain's ability to identify correlations, and patterns, studies show that visualizations and graphic representations improve user cognition (Hullman, 2011). The Internet is a platform where millions of people engage in the creation and exchange of information. Indeed, this fact affects individuals in terms of their academic achievement and their social life. According to (Emeka\& Nyeche,2016) the Internet is defined as a large computer network connecting together millions of smaller computers at numerous sites in several nations belonging to thousands of business, government, research, educational and other organizations. For Internet users, the internet is a worldwide community - one with a very active life. In today's world, the Internet plays a vital role in the teaching, research and learning process in academic institutions. Thus, the advent of the Internet has heralded the emergence of a new form of knowledge production and distribution in a soft form.

Since the 1960s, the British scientist Tony Buzan has designed and invented mind maps, moving away from the use of traditional note taking and encouraging students to take notes using words and images and colors. This is because when doing so, humans use both the left and right hemispheres of the brain, as text and images each stimulate the opposite side. Indeed, data integration coding supports students to increase the number of concepts they learn for a longer time (Buzan 2002).

A study conducted by (Dhindsa, Kasim\& Anderson, 2010) supported Constructivist theory, as it showed that the achievement of students who learned using mind maps in a constructive learning environment was higher and had higher statistical differences than students who had learned in a traditional way.

The perspective of (Buzan,2006) confirms the mind maps function in a similar way in which the brain does, since they organize knowledge in a radial nature. Based on previous theory that electronic mind maps rely on the presentation of information in a specific way. To clarify, they present new information and link it to the previous information given, thus organizing it in a meaningful way, as stipulated in the theory of constructivist.

The objective of a study carried out by (Nong et al., 2009) was to examine the impact of using digital Mind Maps as an approach in comparison with paper-based mind maps and a conventional teaching approach, in terms of academic achievement and attitudes in those teaching and learning psychology. The study sample was comprised of 90 first year students, who were divided into two groups (quasi-experimental design). The experimental group were taught using the digital mind map approach, control group 1 were taught using an 
ordinary approach, and control group 2 were taught using the paper-based mind map method at Thai Nguyen Teacher Training Institute. The measuring tool was an achievement test and a survey. The results showed that there was a significant positive difference in learners' achievement and attitudes toward learning psychology among those who used a computer-based mind mapping learning and teaching approach. Therefore, highlighting that digital mind mapping is a helpful tool when studying.

Another study carried out by (Alomari,2019) aimed to examine the effect of using electronic mind maps as an approach compared to a conventional teaching approach on the academic achievement of those studying a during a course on Arabic language reading in Jordan. The study sample was comprised of 65 fourth grade students, who were divided into two groups (quasi-experimental design).The experimental group consisted of 31 students who were taught using an electronic mind map approach, and the control group, which was comprised of 34 students, who were taught using an ordinary approach. The measuring tool was an achievement test. The results showed a statistically significant difference between the two groups in favor of the experimental group, which was attributed to the use of electronic mind maps.

The objective of a study carried out by (Alsoaydi,2019) was to examine the impact of using electronic mind maps as an approach over a conventional teaching approach on academic achievement and motivation among those learning mathematics in Assir. A quasiexperimental design was adopted in this study. The study sample was comprised of 120 female students, who were divided into two groups: an experimental group of 60 students was taught using the electronic mind map approach, and a control group of 60 students was taught using an ordinary approach. The measuring tool was an achievement test and a motivation scale. The results showed that there was a significant difference in learners' achievement and motivations at the 0.05 level in mathematics in favor of the experimental group. There was also a positive correlation and a statistical significance between the students' scores in both the achievement test and motivation scale at the 0.05 level in mathematics learning. The study recommended designing teacher's guides based on electronic mind maps.

(Jbeili,2013) conducted a study that aimed to examine the impact of using digital mind maps as an approach on sixth grade students' academic achievement during a teaching program in Saudi Arabia. The study sample was comprised of 44 students, who were divided into two groups (quasi-experimental design): an experimental group was taught using the digital mind map approach, and the control group was taught using manual mind maps. The measuring tool was an achievement test. The results showed that there was a statistically significant difference between the means scores of the control and experimental group, and a statistically significant difference between the means scores related to the experimental approach. Indeed, they showed that teaching using digital mind maps improved individuals' achievements more than the use of manual ones. In short, digital mind maps can simplify concepts and maintain learners' attention, thus making it easier for learners to cope with complex data.

A study carried out by (Sabbah,2015) aimed to examine the impact of college students' self-generated computerized mind maps on their reading comprehension and their attitudes toward the subject of generating computerized mind maps for reading comprehension. The study sample was comprised of foundationlevel students who were learning English as a second language (ESL) at the Community College of Qatar. It comprised of 44 students, who were divided into two groups (quasi- 
experimental design): an experimental group of 14 students were taught to read texts via students' self-generated electronic mind maps, and a control group comprised of 8 students, who were taught using teacher-generated whiteboard maps. ANCOVA was used to analyze students' scores on the post-test. The measuring tool was an achievement test and a survey. The results showed that there was a statistically significant difference between the means scores of the control and experimental group, and a statistically significant difference between the means scores in relation to the experimental approach, and that the attitudes toward computerized mind maps were positive.

The objective of a study carried out by (Kizilgol et al., 2016) was to determine the effect of using concepts mapping and a conventional method on the academic achievement of learners studying cost accounting. The study sample included 28 students who used concept mapping and formed the observation group, and a control group comprised of 28 students, who use a traditional approach. The quasi-experimental design was the base of study. The results showed that there was a significant difference between the average scores of the control and observation groups, which revealed that the observation group performed better. Indeed, the average scores of the observation group decreased less than that of the control group $(0.68<3.00)$, thus it was concluded that concept mapping was a more effective method.

(Mohaidat,2018) conducted a study that examined the impact of using electronic mind maps (IMindMap) as an approach during a course to improve the reading comprehension on the ninth-grade students in Jordan. The study sample was comprised of 60 students, who divided into two groups (quasiexperimental design): an experimental group of (30) students was taught using the electronic mind map approach and the control group of (30) students was taught using a traditional approach. The measuring tool was an achievement test. The results showed a significant difference at the level $\mathrm{p} \leq 0.05$ between the means scores of the control and experimental group, in favor of the experimental group. In short, the effect of electronic mind maps on the teaching of reading texts was medium. The study's recommendation was to train both teachers in general, and English teachers in particular, how to design electronic mind maps and apply them in their teaching practices.

The aim of a study carried out by (Alzyoud et al., 2017) was to examine the impact of using an electronic mind map approach to improve students' writing performance in Jordan. The study sample was comprised of 40 students at Alhashymiah School, who were divided into two groups (quasi-experimental design): an experimental group of (20) students was taught using electronic Mind Maps approach, and the control group of (20) students was taught using the traditional approach. The measuring tool was an achievement test. The results showed a significant difference at the level $\mathrm{p} \leq$ 0.05 between the means scores of the control and experimental group, in favor of the experimental group. In short, the effect of electronic mind maps on teaching reading texts was medium. The study's recommendation was to train both teachers in general, and English teachers in particular, how to design electronic mind maps and apply them in their teaching practices.

(Aljaser,2017) examined impact of electronic mental mapping on knowledge female learners at elementary school while studying English, in comparison to those taught using the traditional teaching method adopted from the teacher's guide and their perceptions. The study sample was made up of 30 Saudi female learners, whose ages ranged from 10 to 12 years old that were divided into two groups: an 
experimental group (15), which was taught using electronic Mind Maps, and a control group (15), which was taught using a traditional method. The study revealed that experimental performed better than control groups in test and attitudes toward learning due to electronic mind maps were effective. Thus, indicating that teaching using electronic mind maps increases the individuals' understanding of English and improves their attitudes toward learning the English language. According to (Elsaeed,2012) electronic mind maps are an active which results improved knowledge being organized that supports the reading, retrieval of information, and connection concepts. This is done by using lines or arrows which represent the relationship between concepts, which are either written as words or phrases on the lines that connect two concepts. They were employed as a procedural or instructive approach, and an assessment method.

Two models of mind maps: regular mental which drawing handy on sheet and electronic mental mappings, which use through computer programs that automatically creates parts of thoughts of centralized theme. Also, concepts can be corrected or moved through, while pictures and icons has been put. E-mind maps are showed the relationships of knowledge and thoughts, and involve individuals' natural intellectual (Abdulbaset, 2016). Accordingly, this strategy can be used for teaching multimedia to accomplish its objectives.

Electronic mind maps are used to represent relationships between ideas and information, and require natural thinking in people (Abdulbaset, 2016). Accordingly, this strategy can be used to teach multimedia to achieve its goals.

A study by (Alomari\& Alhorani,2019) aimed to explore the impact of using electronic mind map on fourth graders' Arabic reading comprehension in Jordan. The sample of study was 67 learners. The quasi-experimental design approach was conducted on an experimental group of (32) students, which was taught using an electronic mind map approach and a control group (35), which were taught by a traditional method. The measuring tools included a pre and post achievement test. The results showed that that there was a statistically significant difference in the posttest scores in favor of the experimental group. Thus, it can be concluded that using electronic mind map increases the academic achievement of students.

Benefits of previous studies: The results of the studies described previously serve as a starting point for the subject of this research. They guided the researcher in the development of the quasi-experimental design, the procedures for application, and the discussion of the results and their interpretation.

Differences between the current study and the previous studies: Previous studies have primarily focused on the employment of emind maps in teaching and learning in primary or high school education, while only a few studies have been conducted at universities. Therefore, this research focuses on the use of static and dynamic infographics to teach the Multimedia Concepts Unit, which had not been included much in previous studies at the College of Education at Al-Baha University.

\section{MATERIALS AND METHODS RESEARCH DESIGN}

The study belongs to the experimental design class (a quasi-experimental design), was based on the use of experimental, and control groups to determine the influence of the independent variables on a dependent variable, specifically improvements in the understanding of multimedia concepts, which were measured by an achievement test. The main study was conducted using e-mind maps over 4 weeks, including the achievement test stage, which both were made by the researcher of this study. 
The study aimed to prove the theory that students' achievements could improve through the use of e-mind maps in the classroom. A sample of learners from the college of education at Al-Baha University participated in classes that were taught using both texts and images. A quantitative data collection process was selected to provide a general picture of the research problem, and the t-test method was used in this study to analyze the data. The goal of the descriptive design was focused on two aspects: e-mind maps use and student achievement.

The quasi experimental design approach included a pre-test and post-test used in the current study. The experimental and control groups consisted of students that had not dealt with e-mind maps before and who had been taught by the researcher prior to the experiment. When introducing to students the lesson objectives and appropriate teaching approach for multimedia concepts unit, electronic mental maps approach for teaching and period of multimedia concepts, teaching tools and resources used by the teacher were also given.

The content of lesson was given to a group of reviewers in multimedia. According to their views, the required adjustments and an experimental manual were made and the collection was prepared in its final form. The pre-achievement test was administered to the experimental and control groups. Multimedia concepts was taught using electronic mind maps for experimental with instructions, whereas control groups was taught using a traditional approach. Then, the post- test was given to both study's groups. Then, the data were collected and appropriate statistical processing was performed.

\section{POPULATION}

The entire population for this college of education is 1080 male college learners and 1443 female college learners at Al-Baha University. Table 1 shows the design of the two experimental groups, with the independent variable being the electronic mind maps. The dependent variable is students' achievement.

Table 1 The experimental study

\begin{tabular}{|ccccc|}
\hline Group & Pretest & Manipulating & Posttest & \\
\hline $\begin{array}{c}\text { The } \\
\text { experiment } \\
\text { (20 learners) }\end{array}$ & $\begin{array}{c}\text { Achievement } \\
\text { pretest (O1) }\end{array}$ & $\begin{array}{c}\text { Teaching using } \\
\text { e-mind maps } \\
\text { (X1) }\end{array}$ & $\begin{array}{c}\text { Discussion } \\
\text { and } \\
\text { Achievement } \\
\text { posttest (O2) }\end{array}$ & $\begin{array}{c}\text { interpretation } \\
\text { of findings }\end{array}$ \\
\cline { 1 - 1 } $\begin{array}{c}\text { The control } \\
\text { (20 learners) }\end{array}$ & & $\begin{array}{c}\text { Teaching using } \\
\text { traditional } \\
\text { method (X2) }\end{array}$ & \\
& & & \\
\end{tabular}

\section{PARTICIPANTS}

The sample of the study included (40) students. The sample was chosen randomly with the availability of a computer, the Internet, possessing computer skills, dealing via the web, sharing and interacting with the division of the sample into experimental group (20) students and control group (20) students.

\section{THE PROCEDURE OF THE STUDY}

A pilot study was conducted prior to the original study to ensure the reliability of this study instruments. The researcher conducted a pilot study with just 20 students to identify the time taken to conduct the main study and any potential obstacles. The results of the pilot study indicated that there were no obstacles. Following this, forty learners from the College 
of Education were selected to take part in the main study. They were included in the study after being parity tested. The main study consisted of the first experimental group, which was composed of 20 learners who were taught using e-mind maps, while the control group was composed of 20 learners who were taught using a traditional method. Because a random distribution of participants in the research group was prohibited according to university management policies, the study was conducted on students in their original sections. However, pre-experimental measures were incorporated to ensure the equivalence of research groups for the study. The assignments for the students in the experimental group included looking at and discussing multimedia concepts, presented in the form of text and images, whereas the control group listened to their teacher's lectures. At the end of the sessions, the test was administered to the participants in both the experimental and control groups as a post-test. The steps taken by the researcher are given below:

1. Reviewed the literature and previous studies related to the visual approach, its strategies, charts, and e-mind maps.

2. Identified the list of multimedia concepts in education: the researcher examined the concepts, analyzed the content of unit, then set a specification table of goals, prepared the study tool (achievement test), interviewed college instructors, and then showed them the content analysis.

3. Designed the study scenario, including the lesson materials containing a mixture of two text and images multimedia.

4. Divided the sample into two groups.

5. Explained the Multimedia Concepts Unit using texts and images in the form of electronic mind maps as the teaching method for the experimental group, while the ordinary method of teaching was used for the control group.

6. Applied the pre achievement test to measure the equalization of both groups then the post-test to measure the significant difference between them in terms of achievement.

7. Explained and analyzed the results.

8. Selected the ADDIE design model to design the Multimedia Concepts Unit using texts and images in the form of e-mind maps.

\section{STUDY TOOLS}

In light of the previous definition of study terms, interpretation and analysis of the philosophical foundations related to the problem of study through related previous studies. The study tools were extracted for application using the electronic mind maps, as follows:

\section{ACHIEVEMENT TEST}

The goal of the test: Measuring the students' achievement after study the subjec design and produce educational materials with electronic mind maps strategy according to Bloom's cognitive levels.

Test description: The test items were formulated in the form of objective questions (multiple choice). Each item has four choices, one of which represents the correct answer in light of the content of multimedia concepts in the course of designing and producing educational materials with the total score (30) grades.

The specifications table: The specifications table was built based on Bloom's cognitive levels, which are (remember, understand, and apply). The items related to each level of cognitive goals for Bloom was determined to be achieved for each topic, as the number of test items was (30) goals, ten items for each goal. Table 2 shows the reliability of the test. 
Table (2) Test Reliability

\begin{tabular}{|ccccc|}
\hline $\begin{array}{c}\text { Reliability } \\
\text { coefficient } \\
(\mathrm{r} 1,1)\end{array}$ & $\begin{array}{c}\text { Variation of } \\
\text { grades (a2) }\end{array}$ & $\begin{array}{c}\text { Standard } \\
\text { deviation (a) }\end{array}$ & $\begin{array}{c}\text { Average of } \\
\text { grades (m) }\end{array}$ & $\begin{array}{c}\text { Final grade } \\
(\mathrm{n})\end{array}$ \\
\hline 0.81 & 33.45 & 4.12 & 23.73 & 30 \\
\hline
\end{tabular}

To ensure test validity (content validity), the researcher offered the test in its preliminary form to a group of specialists in teaching computer skills (I.T. teachers) to calculate its validity. There were five jury members, to ensure the reliability of each question of the test, namely its clarity, reliability of objectives and linguistic content.

The test results in Table 2 indicate that the reliability coefficient of the test was 0.81 , which in turn demonstrates that the test had a high level of reliability. The researcher ensured the reliability of the test by observing the students' performance and assessing them in each area of knowledge. The level of perfection was set as 30, with 30 indicating

Table 3. Correlation coefficients between the degree of each level and the total score of the achievement test

\begin{tabular}{|l|l|l|}
\hline $\mathrm{N}$ & Level & $\begin{array}{l}\text { Correlation } \\
\text { coefficients }\end{array}$ \\
\hline 1 & Comprehension & 0.541 \\
2 & Recall & 0.642 \\
\hline
\end{tabular}

Table 3 indicates that the correlation coefficients were between the score of each level, and the total score of the test ranged between 0.541 and 0.642, which are statistically significant at a level of significance less than 0.01 . This finding indicates that the items of each test level are valid.

The pilot study consisted of 20 learners. To define the test time, the first 10 students finished the test within 25 minutes, while the other 10 finished the test within 30 minutes, so that the student had completed the task perfectly, and 0 in cases when students showed a complete inability to complete the task. The same process was repeated after one week. The Pearson correlation factor between the students' marks in the two previous observations was calculated as 0.86 , indicating that that the test was reliable and ready for application.

The Spearman correlation coefficient was calculated on the scores of the sample between the total score of 10 for the 10 comprehension questions and the 20 recall questions. Table 3 shows the results of the correlation coefficients. the average was 27 minutes. Cronbach's alpha value was 0.61 , which indicates it was of high validity. In order to determine the difficulties facing the researcher when applying the study, the coefficients of ease and difficulty were calculated. It was clear from that the coefficients of ease that they ranged from 0.66 to 0.40 and that the difficulty coefficients for the paragraphs ranged from 0.33 to 0.31 . Therefore, the coefficient of ease or difficulty were around $40 \%$. 


\section{Analyzing electronic mind map use in education}

The literature and previous studies related to emind maps and their impact was revised to prepare the theoretical framework of the study. The undergraduate students were the target audience of study and they looked at and discussed electronic mind maps. The study was conducted in the computer lab where students and the teacher had access to the Internet. The Multimedia Concepts Unit was the focus content, as it contains more visual concepts to create multimedia concepts. The experimental group studied the unit with the aid of texts and images, and the control group with the aid of a conventional method.

\section{The design of electronic mind map use in education}

The e-mind maps designed by the researcher contained four images and texts (xmind) including 30 multimedia concepts. In order to attract learners' attention to the e-mind maps, data was presented clearly using codes, color and consistency. The scenario for texts and images was drawn. The achievement test was based on recall and cognitive goals, and was comprised of 30 multiple choice questions to measure students' memory and comprehension. Then, a specification table was made including the number of questions to measure the impact of e-mind maps on students' achievements.

\section{The development of electronic mind map use in education}

The researcher designs the e-mind maps based on the content from the Multimedia Concepts Unit, specifically on 30 computer concepts. The researcher first started the production and testing of the methodology, then showed it to number of reviewers in the technology department to check the clarity of the screen, availability, and the basics of building e-mind maps. The researcher conducted a pilot study of 20 learners, who were not included in the sample used in the main study to identify any obstacles, and verify the time needed for conducting the main study (total of means/number of students). The results of pilot study indicated that there was no obstacles that had to be overcome to apply the program and the time needed was an hour for each each lecture. Following that, the measurement tool was applied during the posttest, data were recorded and monitored, and then the data were processed statistically, before the results were analyzed and discussed. Finally, recommendations and suggestions were made in light of the results.

\section{Implementation stage of electronic mind} map in education

The researcher tested the texts and images used in the electronic mind maps, and then revised them in terms of the incidence of patterns, mistakes, and sources by peers, before applying them to the students. The researcher provided students with his email and cellphone number, in case they had any queries related to the use of e-mind maps. The age of the learners was between 20 and 24 years old. There were 40 male learners that participated in the study, all with the ability to deal with visual and auditory data. The subject was taken from the instructional design course, specifically the Multimedia Concepts Unit, in order to increase students' achievement. The instructor trained students to draw e-mind maps using Xmind, taking advantage of the features of that particular program. Each student was evaluated based on individual differences, and the instructor listened to students' thoughts, information and concepts related to multimedia concepts then categorized, spoke to and encouraged them, especially those who struggled to create their e-mind maps. 


\section{The evaluation of electronic mind map use in education}

To determine if the goals had been met, the pre and post-test was made to measure learners' achievements. It considered the feedback from learners. The data were recorded and monitored, and then the data was processed statistically, before the results were analyzed and discussed. Finally, recommendations and suggestions were made in light of the results. Data management and statistical analysis were conducted using a statistical package for the Social Sciences (SPSS), specifically the T-test, Arithmetic Averages, standard deviation and Eta square.

Table4: Content Analysis by the Researcher

\begin{tabular}{|c|c|c|}
\hline Content Analysis of concepts & Number of items & $\begin{array}{l}\text { Points of } \\
\text { difference }\end{array}$ \\
\hline 30 & 30 & $91 \%$ \\
\hline
\end{tabular}

Table 4 shows that the stability coefficient was $91 \%$. This indicates a high stability of the analysis. Based on the results of the analysis, the list of educational objectives was determined .The researcher established the relative weights of the subjects, as well as ascertained the relative weights of the cognitive levels (remembering understanding) by determining the number of questions related to the subject matter and determining the number of questions that were related to each level of knowledge in light of the list of objectives and cognitive concepts. The following is a presentation of the specification table for the cognitive test related to the concepts of educational technology.

Ease, difficulty, and discrimination coefficient: Ease, difficulty, and discrimination coefficients for test vocabulary: The corrected ease coefficient was calculated taking into account the effect of guesswork, difficulty, and the discrimination coefficient for each of the test items
The evaluation phase consists of two parts: formative and summative. Formative evaluation is present at each stage of the ADDIE process. Summative evaluation consists of tests designed for domain specific criterion-related referenced items and provides opportunities to obtain feedback from the users. The achievement test was conducted to measure the study achievement of both the experimental and control groups.

The researcher analyzed the content of the Multimedia Concepts Unit (comprehension and recall goals). Table 4 shows the values of these transactions.

(according to the coefficient of corrected ease of estimation effect) through the results of the application of the test on the survey sample. To calculate the coefficient of ease and difficulty of the test as a whole, the coefficient of ease and difficulty, and the coefficient of discrimination were taken as: coefficient of ease (1.1), coefficient of difficulty (3.0) and coefficient of discrimination (0.21). Figure 7 indicates the last stage of the instructional design (ADDIE model) of the study.

RESULTS AND DISCUSSION There has no effect on learners' achievement of experimental group with electronic mind maps and control group with traditional method during the pre and post-tests as a result of implementing the program.

To answer this assumption, a timed pre-test and post-test on the multimedia concepts was administered. The mean scores and standard deviation of the students' scores on the pre-test and the post-test were calculated based on the differences between the two levels of 
instructional delivery, electronic mind maps strategy, and traditional method, as shown in
Table6. The pre-test was conducted to assure the equalization of the two groups.

Table 5 mean scores and standard deviation of students' achievement on pre-test per electronic mind maps

\begin{tabular}{|l|c|l|l|l|l|l|}
\hline \multicolumn{1}{|c|}{ Group } & $\mathrm{N}$ & Mean & $\begin{array}{c}\text { Std. } \\
\text { Deviation }\end{array}$ & T value & df & $\begin{array}{c}\text { Sig. (2- } \\
\text { tailed) }\end{array}$ \\
\hline Experimental & 20 & 13.60 & 3.70 & & & \\
\hline Control & 20 & 12.32 & 3.10 & 6.952 & 38 & .067 \\
\hline
\end{tabular}

Table 5 showed there were no statically significant differences between the mean scores of the experimental group, who used emind maps, and the conventional group, who were taught using a traditional approach, on the pre-test to determine their achievement. As $\mathrm{p} \leq 0.05$ that means the null hypothesis was accepted. The results of the post achievement test are shown in Table 6.

Table 6 Mean scores and standard deviation of students' achievement on post-test per electronic mind maps

\begin{tabular}{|c|c|c|c|c|c|c|c|}
\hline Test & Group & $\mathrm{N}$ & Mean & Std. Deviation & $\mathrm{T}$ & d.f & Sig. (2-tailed) \\
\hline \multirow{2}{*}{$\begin{array}{c}\text { Post- } \\
\text { test }\end{array}$} & Experimental & 20 & 29.45 & 4.12 & \multirow{2}{*}{24.460} & 28 & .000 \\
\cline { 2 - 8 } & Control & 20 & 24.69 & 3.51 & & \\
\hline
\end{tabular}

The results of the study analysis in Table 6 showed the results of the experimental group of 20 students and a control group of 20 students $(\mathrm{N}=40, \mathrm{p} \leq 0.05)$. In terms of students' achievements, the experimental group (taught using e-mind maps) reported a means of $\bar{x}=29.45$ in the posttest, with a standard deviation of $\sigma=4.12$, which indicted an improvement if compared to 24.69. While the control group (taught using a traditional method) reported a mean score of $\overline{\mathrm{x}}=24.69$ posttest, with a standard deviation of $\sigma=3.51$. The results indicated that there were statistically significant differences in the achievement mean groups

In addition, after running a t-test on the experimental group, it showed that the experimental group outperformed their counterparts in the control group. The results indicate that the use of the e-mind maps strategy can influence students' achievements in the subject of multimedia concepts. This was due to that e-mind maps simplified knowledge to students with comments. Moreover, e-mind mappings were more effective than traditional methods, as they are printable, used on the Web, present information in one image, are easy to create, explain concepts in a simple way, and present information attractively. The maps also allow the fast revision of topics before a test. In addition, hey help learners to link information to colors and material items, which contributes to learners being able to focus on the subject in their minds. Furthermore, students in the experimental group experienced quality instruction that was student-centered and student-focused. The e-mind maps also allowed for improved use of class time, and utilized various instructional strategies, including texts and images-based learning structures. While research into the effectiveness of the e-mind maps on 
instruction is limited, this research study has provided additional, valuable information regarding the model's impact on students' achievement. What is more, although the use of e-mind maps is a relatively new instructional approach, it certainly has the potential to be deemed effective in terms of improving student achievement in the undergraduate classroom, if not every classroom.

This result is consistent with many other studies on the subject (Balim, 2013); (Jbeili,
2013); (Boyson, 2009); (Elshahrany, 2010); (Elawfy, 2011); (Abi El-Mona \& Abdel Khaliq, 2012);( Hallen\& Sangeetha, 2015), that revealed that the electronic mind maps technique improved students' learning when compared to the traditional method. Hence, (Elqasemia,2010) and (Elabady \& Jradat,2015) stated the electronic mind maps technique could be regarded as invaluable for enhancing students' learning. The researcher calculated the measures of association of this study. Table 7 shows the values of these transactions.

\section{Table 7 Measure of association}

\begin{tabular}{|l|l|l|}
\hline \multirow{2}{*}{ Post-test group } & Eta & Eta Squared \\
\cline { 2 - 3 } & .912 & .924 \\
\hline
\end{tabular}

Table 7 shows the eta squared for the total grades of the posttest for the subject of instructional design for the study sample (.924), which is equal to $92.4 \%$ from the grade changes of the posttests for both study groups, in favor of the experimental group that was taught using electronic mind maps method. It concluded from the above that the use of electronic mind maps improved the level of lesson multimedia concepts by up to $92 \%$.

\section{CONCLUSION}

The study aimed to identify the effect of the electronic mind map strategy while teaching multimedia concepts on students' achievement. The study confirmed that the electronic mind map strategy increased students' achievement when compared to the traditional delivery approach based on the test scores. Thus, it is concluded that e-mind maps are effective for teaching and learning multimedia concepts. The study recommended using e-mental mappings in university education and measuring its impact on achievement.

\section{RECOMMENDATIONS FOR THE} STUDY

1- Using the electronic mind maps instead of traditional learning in teaching students.
2- Providing computers and internet services in some universities in the Kingdom of Saudi Arabia where this service is not available, to enable members and students to benefit from them and use them in providing appropriate educational strategies to integrate technology in the educational process.

3 - Increasing interest in using electronic mind maps in universities by establishing a unit to develop students 'skills.

4. Working on developing educational and computer programs based on electronic mental maps.

\section{SUGGESTIONS FOR FUTURE STUDIES}

1. More studies are needed to investigate the effectiveness of electronic mind maps on learning in other subjects.

2. As the sample of the current study only included male participants from the College of Education at Al-Baha University in Saudi Arabia, future studies are needed to include females and participants from other cities and countries.

3. Conducting another study to identify the effectiveness of electronic mind maps in raising the efficiency of the educational process in its various aspects. 


\section{REFERENCES}

Abdulbaset, H. M. (2016). Digital Mind Maps: Their activities in education and learning. E-Learning Journal, 12.

Abi El-Mona, I., \& Abdel Khaliq, F. (2011). The influence of mind mapping on English graders' science achievement. School Science and Mathematics, 108(7), 298-312. https://doi.org/10.1111/j.19498594.2008.tb17843.x

Aljaser, A.M. (2017). The Effectiveness of Electronic Mind Maps in Developing Academic Achievement and the Attitude towards Learning English among Primary School Students. International Education Studies, 10(12),80-95.

Alomari, A.M.(2019). Using Mind Mapping Technique to Improve Reading Comprehension Ability of Fourth grade Arabic Language Students in Jordan. IOSR Journal of Humanities and Social Science, 24(1),53-58.

Alomari, A.M.,\&Alhorani,M.E.(2019).The effect of using electronic mind map as a medium of instruction on fourth garders' Arabic reading comprehension in Jordan. International Journal of Innovative Science and Research Technology, 4(3), 744-748.

Alsoaydi, H.A.(2019)The Effectiveness of Using Electronic Mind Maps in Developing Middle Stage Gil students' Achievement and Motivation in Assir. IUG Journal of Educational and Psychology Sciences,27(1), pp 300 -324.

Alzyoud, A.A., Aljamal, D., \& Banianbdelrahman, A.(2017).Mind Mapping and students writing performance. Arab World English Jouranl,8(4), 280-291. DOI: https://dx.doi.org/10.24093/awej/vol8no $\underline{4.19}$

Buzan, T. (2002). Mind maps. Hammersmith, London: Thorsons/HarperCollins.
Buzan, Tony (2005). The Ultimate book of mind maps. Thailand: Imago.

Buzan, Tony (2006). The mind map book. BBC Books: London.

Dhindsa; H.S.,Kasim, M.,\& Anderson, R (2010). Constructivist visual mind map teaching approach and the quality of students cognitive structures. Journal of Science Education and Technology, 20(2), 186-200.

Elawfy, A. S. (2011). The effectiveness of using e-Mind Maps in the achievement of English grammar for the secondgrade secondary female students. (Unpublished master's thesis). King Abdulaziz University,Jeddah, Saudi Arabia.

Elsaeed, E. A. (2012). Educational e-Mind Maps. Arab eLearning Academy.

Elshahrany, M. (2010). The impact of utilizing electronic mind maps through the web in teaching geography on the achievement of students in the intermediate second grade and their attitudes towards it. (Unpublished doctoral's thesis), Umm Al-Qura University, Makkah, Saudi Arabia.

Hawrany, H. (2011). The impact of utilizing mind maps on the achievement of ninthgrade students in science and their attitudes toward science in public schools in Qalqilia. (Unpublished master's thesis), An-Najah University, Nablus, Palestine.

Jbeili, I. M.A (2013). The Impact of digital Mind Maps on science achievement among sixth grade students in Saudi Arabia. Procedia-social and behavioral sciences, 103, 1078-1087. https://doi.org/10.1016/j.sbspro.2013.10. 435

Kizilgol, O., Kilic, B.I.,\&Abdioglu, H.(2016). The effects of using the concept mapping and the traditional method on the academic achievement of students in 
learning the fundamental topics of cost accounting. Journal of Business, Economics and Financ,5(2),171-190. DOI:

10.17261/Pressacademia.2016219260

Mayer, R. E. (2003). The promise of multimedia learning: Using the same instructional design methods across different media. Learning and Instruction, 13 (2), 125-139

Mohaidat, M.M.T. (2018). The Impact of Electronic Mind Maps on Students' Reading Comprehension. English Language Teaching, 11(4),32-42.

Nong, B., Pham, T. A., \& Tran, T. N. M. (2009). Integrate the digital mind mapping into teaching and learning Psychology. Teacher Training component-ICT, VVOB Education Program Vietnam.
Reiser, R. A., \& Dempsey, J. V. (2007). Trends and Issues in Instructional Design and Technology. Upper Saddle River, N.J.: Person Education, Inc.

Sabbah, S.S.(2015).The effect of college students' self-generated computerized mind mapping on their reading achievement. International Journal of Education and Development using Information and Communication Technology, 11(3),4-36.

Wu, P.H., Hwang, G.J., Milrad, M., Ke, H.R.,\& Huang, Y.M.(2012). An innovative concept map approach for improving students' learning performance with an instant feedback mechanism. British Journal of Educational Technology,43(2),217-232. 


\title{
فاعلية استخدام خرائط ذهنية إلكترونية لتتمية مفاهيم الوسائط المتعددة لاى الطلاب في جامعة الباحة
}

\author{
د. عبدالله بن خليفة العديل \\ أستاذ مشارك بقسم تقنيات التعليم، كلية التربية، جامعة الباحة لفيله
}

مستخلص. لقد أعطى ظهور تقنيات الويب ·. r فرصًا جديدة في مجال مفاهيم الوسائط المتعددة. تستخدم الخرائط الذهنية الالكترونية لتقديم المعلومات بتسيق مثير وسريع، وتوفير الوقت وإبعاد المتعلمين عن الملل. تعد الخرائط

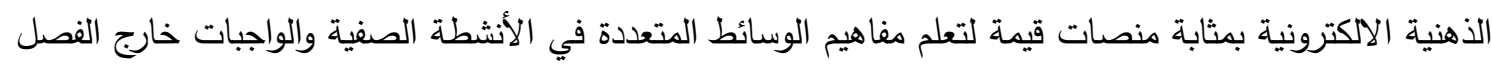
لتتمية تحصيل الطلاب. لذلك يركز هذا البحث على استخدام الخرائط الذهنية الالكترونية (xmind) لتدريس مفاهيم الوسائط المتعددة لطلاب البكالوروس بكلية التربية، جامعة الباحة. هدفت الدراسة إلى الكثف عن فاعلية الخرائط

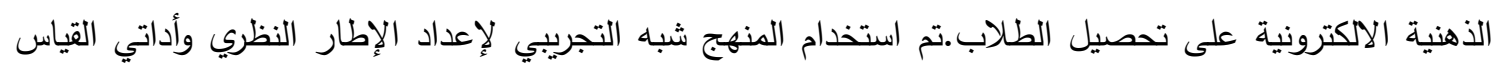

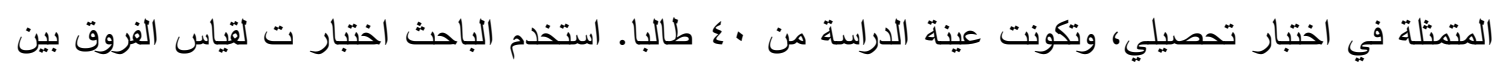
المجموعة التجريبية التي درست عن طريق الخرائط الذهنية الاككترونية (نص وصور) وتم تدريس المجموعة الضابطة باستخدام (الطريقة الاعتيادية). أسفرت النتائج عن وجود فروق ذات دلالة إحصائية عند مستوى دلالة

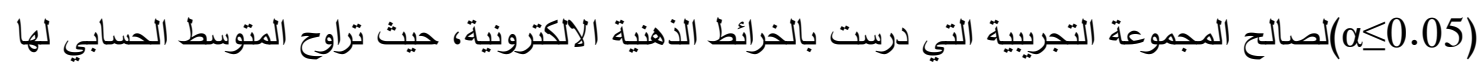

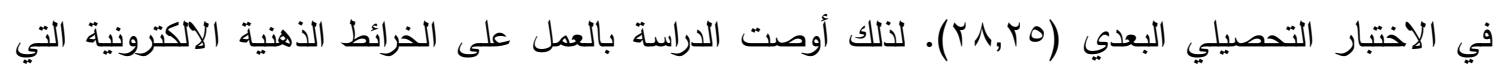
تحتوي على صور ونصوص في تدريس التصميم التعليمي في التعليم الجامعي وقياس مدى فاعليته على التحصيل الاراسي في تتمية بعض مفاهيم الوسائط المتعددة. الكلمات المفتاحية: فاعلية؛ الخرائط العقلية المحوسبة؛ الوسائل المتنوعة؛ جامعة الباحة. 